\title{
Outcomes after coverage of lenticulostriate vessels by flow diverters: a multicenter experience
}

\author{
Kathryn M. Wagner, MD, ${ }^{1}$ Visish M. Srinivasan, MD, ${ }^{1}$ Aditya Srivatsan, MS, ${ }^{1}$ \\ Michael G. Z. Ghali, MD, PhD, MS, ${ }^{1}$ Ajith J. Thomas, MD, ${ }^{2}$ Alejandro Enriquez-Marulanda, MD, ${ }^{2}$ \\ Abdulrahman Y. Alturki, MBBS, MSc, FRCSC, ${ }^{2}$ Christopher S. Ogilvy, MD, ${ }^{2}$ \\ Maxim Mokin, MD, PhD, ${ }^{3}$ Anna L. Kuhn, MD, PhD, ${ }^{4}$ Ajit Puri, MD, ${ }^{5}$ Ramesh Grandhi, MD, ${ }^{5}$ \\ Stephen Chen, MD, ${ }^{6}$ Jeremiah Johnson, MD, ${ }^{1}$ and Peter Kan, MD, MPH, FRCS ${ }^{1}$
}

Departments of ${ }^{1}$ Neurosurgery and ${ }^{6}$ Radiology, Baylor College of Medicine, Houston, Texas; ${ }^{2}$ Department of Neurosurgery, Beth Israel Deaconess Medical Center, Harvard Medical School, Boston, Massachusetts; ${ }^{3}$ Department of Neurosurgery, University of South Florida, Tampa, Florida; ${ }^{4}$ Department of Radiology, University of Massachusetts Medical School, Worcester, Massachusetts; and ${ }^{5}$ Department of Neurosurgery, University of Texas at San Antonio, Texas

\begin{abstract}
OBJECTIVE With the increasing use of flow diversion as treatment for intracranial aneurysms, there is a concomitant increased vigilance in monitoring complications. The low porosity of flow diverters is concerning when the origins of vessels are covered, whether large circle of Willis branches or critical perforators. In this study, the authors report their experience with flow diverter coverage of the lenticulostriate vessels and evaluate their safety and outcomes.
\end{abstract}

METHODS The authors retrospectively reviewed 5 institutional databases of all flow diversion cases from August 2012 to June 2018. Information regarding patient presentation, aneurysm location, treatment, and outcomes were recorded. Patients who were treated with flow diverters placed in the proximal middle cerebral artery (MCA), proximal anterior cerebral artery, or distal internal carotid artery leading to coverage of the medial and lateral lenticulostriate vessels were included. Clinical outcomes according to the modified Rankin Scale were reviewed. Univariate and multivariate analyses were performed to establish risk factors for lenticulostriate infarct.

RESULTS Fifty-two patients were included in the analysis. Postprocedure cross-sectional images were available in 30 patients. Two patients experienced transient occlusion of the MCA during the procedure; one was asymptomatic, and the other had a clinical and radiographic ipsilateral internal capsule stroke. Five patients had transient symptoms without radiographic infarct in the lenticulostriate territory. Two patients experienced in-stent thrombosis, leading to clinical MCA infarcts (one in the ipsilateral caudate) after discontinuing antiplatelet therapy. Discontinuation of dual antiplatelet therapy prior to 6 months was the only variable that was significantly correlated with stroke outcome $(p<0.01,0 R 0.3,95 \% \mathrm{Cl}$ $0-0.43)$, and this significance persisted when controlled for other risk factors, including age, smoking status, and aneurysm location.

CONCLUSIONS The use and versatility of flow diversion is increasing, and safety data are continuing to accumulate. Here, the authors provide early data on the safety of covering lenticulostriate vessels with flow diverters. The authors concluded that the coverage of these perforators does not routinely lead to clinically significant ischemia when dual antiplatelet therapy is continued for 6 months. Further evaluation is needed in larger cohorts and with imaging follow-up as experience develops in using these devices in more distal circulation.

https://thejns.org/doi/abs/10.3171/2018.8.JNS18755

KEYWORDS flow diverters; lenticulostriates; safety; infarcts; interventional neurosurgery

$\mathrm{F}$ Low diversion technology has revolutionized the treatment of intracranial aneurysms that are suboptimal for surgical or traditional endovascular intervention. ${ }^{3,12,13,15}$ While initially approved for large aneurysms in the internal carotid artery (ICA), increased safety and fea- sibility data have allowed for the use of flow diverters in progressively varied pathologies and locations. ${ }^{8,17,20,22}$ The braided endoluminal design is intended to occlude aneurysms while maintaining flow through the parent vessel and any covered branches. ${ }^{14}$ Reports of covering critical

ABBREVIATIONS ACA = anterior cerebral artery; $\mathrm{AChA}=$ anterior choroidal artery; $\mathrm{AICA}=$ anterior inferior cerebellar artery; $\mathrm{DAPT}=$ dual antiplatelet therapy; $\mathrm{DWI}=$ diffusion-weighted imaging; FD = flow diverter; ICA = internal carotid artery; MCA = middle cerebral artery; OphA = ophthalmic artery; PCoA = posterior communicating artery; PED = Pipeline embolization device; PICA = posterior inferior cerebellar artery.

SUBMITTED March 21, 2018. ACCEPTED August 9, 2018.

INCLUDE WHEN CITING Published online January 11, 2019; DOI: 10.3171/2018.8.JNS18755. 
TABLE 1. Baseline clinical characteristics $(n=52)$

\begin{tabular}{cc}
\hline & Value \\
\hline Mean age, yrs & 59 \\
\hline Female, $\mathrm{n}(\%)$ & $39(75)$ \\
\hline Aneurysm location, $\mathrm{n}(\%)$ & \\
\hline ICA & $21(41)$ \\
\hline ACA & $8(16)$ \\
\hline MCA & $23(43)$ \\
\hline
\end{tabular}

branches and perforators have varied, and practitioners are justifiably cautious about deploying these devices over critical vessels.

Flow diversion of distal anterior circulation aneurysms presents such a challenge. Aneurysms of the proximal middle cerebral artery (MCA) and anterior cerebral artery (ACA) require positioning of the flow diverter (FD) so that the device would cover the lateral lenticulostriate branches of the MCA or medial lenticulostriate vessels of the ACA. Occasionally, flow diversion treatment of distal ICA aneurysms (such as anterior choroidal artery [AChA] aneurysms) also requires coverage of the lenticulostriate vessels. Occlusion of these vessels could lead to clinically devastating infarcts. However, certain aneurysms in these locations are considered for FD specifically because they are not amenable to surgical clipping or endovascular coiling because of their complex fusiform morphology and/or giant size. Our previous experience in covering large or essential vessels with FDs did not show clinically significant infarcts, ${ }^{26}$ which is similar to other reports. ${ }^{18,21,23,27,31}$ Here, we present a multicenter experience for treating distal ICA aneurysms and proximal MCA and ACA aneurysms with the Pipeline embolization device (PED; Medtronic) covering medial and lateral lenticulostriate vessels. ${ }^{1}$

\section{Methods}

We retrospectively reviewed 5 institutional databases of all flow diversion cases from August 2012 to June 2018. Cases in which the pathology was in the anterior circulation where the flow diverter either was primarily placed or extended into the $\mathrm{M}_{1}$ or $\mathrm{A}_{1}$, covering the lateral or medial lenticulostriate branches, respectively, were included. Medical records were reviewed for demographic and clinical data. All applicable images were retrospectively reviewed when available. Some of the included centers routinely perform postoperative imaging, while others only pursued imaging if there is a change in the patient's clinical examination findings. The study was approved by each local IRB and the IRB of the coordinating center.

\section{Procedure}

Senior neurointerventional faculty evaluated the clinical presentation and images and formulated the treatment plan for all patients. The decision to use FDs as the treatment method was based on aneurysm morphology, the presence of multiple aneurysms, or surgeon preference. All patients were maintained on dual antiplatelet therapy (DAPT; 81 or $325 \mathrm{mg}$ aspirin and $75 \mathrm{mg}$ clopidogrel) 5 to 7 days prior to elective placement of the FD. Appropriate platelet inhibition was confirmed when available using the P2Y12 assay (VerifyNow, Accumetrics) or light transmission aggregometry. An alternative antiplatelet agent was used in patients who did not respond to clopidogrel to reduce the risk of thromboembolic events. ${ }^{1}$ A P2Y12 reaction unit of $\leq 220$ or a platelet aggregation $<50 \%$ of the maximum in 2 runs of $5-\mu \mathrm{mol} / \mathrm{L}$ ADP (adenosine diphosphate) was considered to indicate an appropriate level of platelet inhibition for treatment.

Patients received heparin systemically during the procedure with an activated clotting time $\geq 200$ seconds throughout the procedure. PEDs were used in all cases and delivered in standard fashion. Patients were observed for a minimum of 1 night. Images were obtained in patients with new neurological symptoms or at the discretion of the attending physician. Patients were maintained on aspirin and clopidogrel/ticagrelor for at least 3-6 months following PED placement and aspirin indefinitely after.

\section{Outcomes}

The modified Rankin Scale was used to monitor clinical outcome, and the scores were assessed at baseline, and 1 day, 3 months, and 6 months postprocedure when available. Using ipsilateral stroke in the lenticulostriate territory as the primary outcome, a Kaplan-Meier survival curve was created. Univariate and multivariate analyses were performed to assess age, smoking status, aneurysm location, and duration of DAPT as risk factors for lenticulostriate territory stroke. Exact logistic regression was done using Stata (version 15, StataCorp).

\section{Results}

Fifty-two patients with aneurysms of the anterior circulation were treated with flow diverters that covered the medial or lateral lenticulostriate vessels. Thirty-eight of the patients were female, and the mean age was 59 years (Table 1). Twenty-three patients had proximal MCA aneurysms, 8 had proximal ACA aneurysms, and 21 had distal ICA aneurysms where the distal portion of the device extended into the $M_{1}$ or $A_{1}$ segment. Ten patients had previously treated aneurysms, but the aneurysms in the remaining patients were incidentally discovered on workup for headaches, stroke, or other pathology. Fifteen patients had fusiform aneurysms that were not amenable to surgical or other endovascular treatment. The mean follow-up was 14 months. All lenticulostriate vessels were covered by a single device.

\section{Imaging Outcomes}

Thirty of the 52 patients underwent imaging at some point after the procedure. As it is not standard to perform imaging in the absence of a change in clinical status, images included CT scans $(n=11)$, MR images $(n=15)$, or both $(n=4)$ and were obtained from 1 day to 4 years postoperatively. Thirteen patients underwent imaging within the 1st week, with the median time to imaging being 3 months. Many of the images were obtained for headache or other symptoms that would not be expected from a lenticulostriate territory infarct. The patients who did not undergo radiographic follow-up were clinically well at last follow-up. 


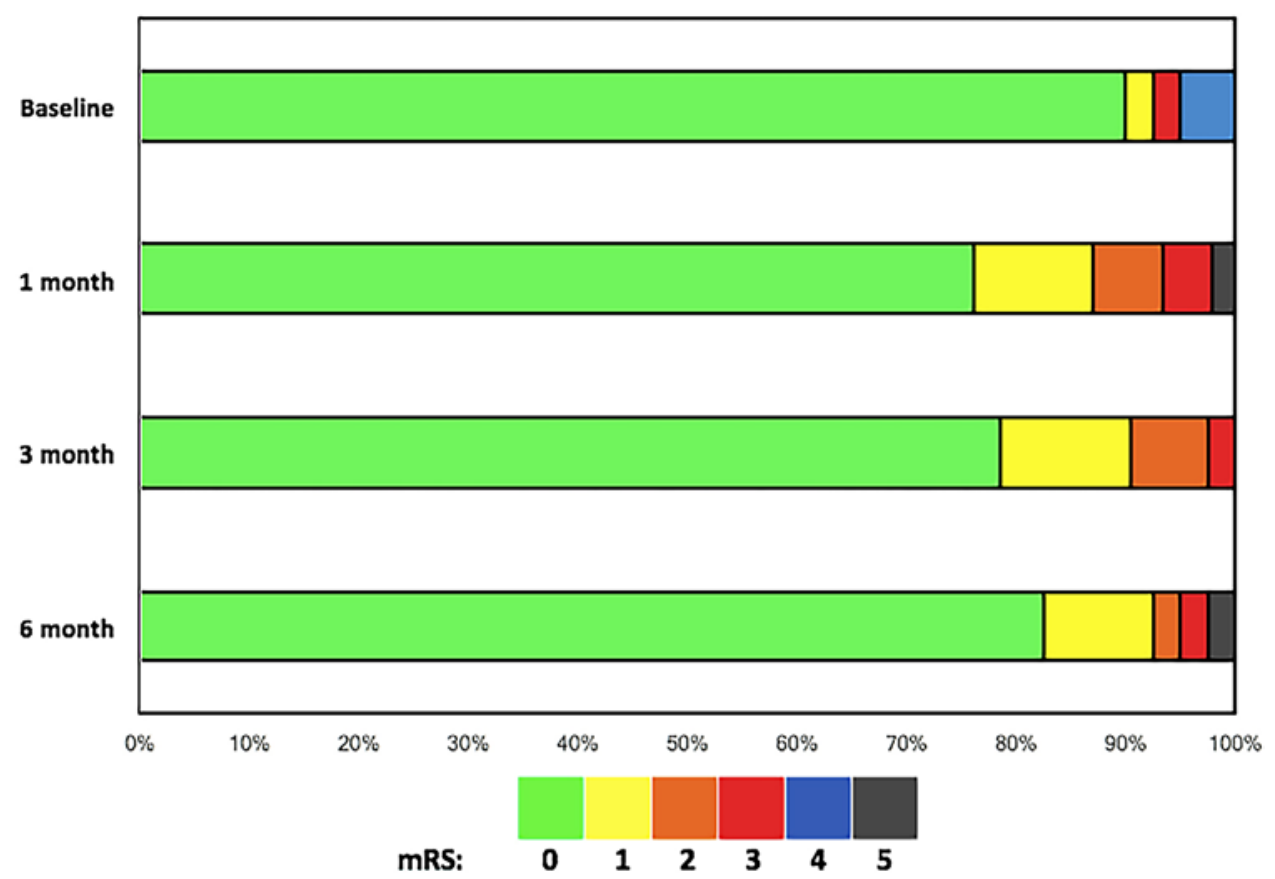

FIG. 1. Modified Rankin Scale (mRS) score at baseline and posttreatment time points up to 6 months. Figure is available in color online only.

\section{Clinical Outcomes}

All patients were examined postoperatively by neurosurgeons and neurocritical care faculty, who made assessments regarding any new neurological deficits or symptoms. Five patients experienced transient symptoms postoperatively. One patient had brief aphasia after placement of an FD in the left MCA that resolved within 24 hours, with CT showing no infarct 7 days after the procedure. A second patient had transient aphasia and right-sided weakness on postoperative day 1 after FD placement in the left ICA, but no infarct was noted on MRI. Three patients had small distal hemispheric changes on imaging, consistent with thromboembolic events, but no infarcts in the lenticulostriate territory, and the symptoms completely resolved.

Two patients experienced transient occlusion of the MCA as the PED was being placed. One patient experienced in-stent thrombosis during the procedure, which resolved with intraarterial abciximab, and had no resulting clinical or radiographic sequela. The other patient had an ACA PED that migrated proximally into the MCA, requiring intraprocedural placement of an Enterprise stent (Codman) in the ipsilateral MCA and treatment with intraarterial abciximab (case 2, detailed below). Postprocedure CT scanning showed an infarct of the posterior limb of the ipsilateral internal capsule. The patient had hemiparesis postoperatively, which improved after inpatient rehabilitation.

Two patients presented with hemiparesis and MCA infarcts due to postoperative stent occlusion. One patient was 10 days postprocedure and had been noncompliant with medication; an emergency thrombectomy was performed successfully. There was an ipsilateral caudate infarct noted on MRI, but the patient was neurologically intact at the last follow-up. The second patient, a heavy smoker, expe- rienced the symptoms 3 months after the procedure when clopidogrel was discontinued; CT scanning showed an infarct in the hemispheric MCA distribution but not in the lenticulostriate territory. Patients' functional status otherwise remained high, and those who had strokes improved over time (Fig. 1). When infarcts did occur, they were immediately posttreatment or within the first 3 months (Fig. 2).

Forty patients underwent angiography at least 6 months after the procedure. Complete obliteration of the aneurysm was seen in $29(73 \%)$ of these patients, and incomplete occlusion was seen in 11 . Of the 29 patients who achieved complete aneurysm occlusion, the average time to complete occlusion was 8.2 months.

\section{Statistical Analysis}

Univariate analysis showed that ending DAPT prior to 6 months significantly increased the risk of stroke in the lenticulostriate territory ( $\mathrm{p}<0.01$, OR $0.3,95 \%$ CI $0-0.43$ ). Other risk factors, including age, aneurysm location, and smoking status, were not significant. Multivariate analysis showed that the duration of DAPT was correlated with stroke outcome when controlling for these other risk factors.

\section{Illustrative Cases}

\section{Case 1}

A 74-year-old woman harbored an MCA aneurysm that was discovered on imaging workup for dementia. Angiography showed a $10-\mathrm{mm}$ right $\mathrm{M}_{1}$ aneurysm with a $5.5-\mathrm{mm}$ neck arising proximal to the bifurcation, projecting superiorly and anteriorly (Fig. 3). This lesion was thought to be appropriate for flow diversion therapy with the PED. The 


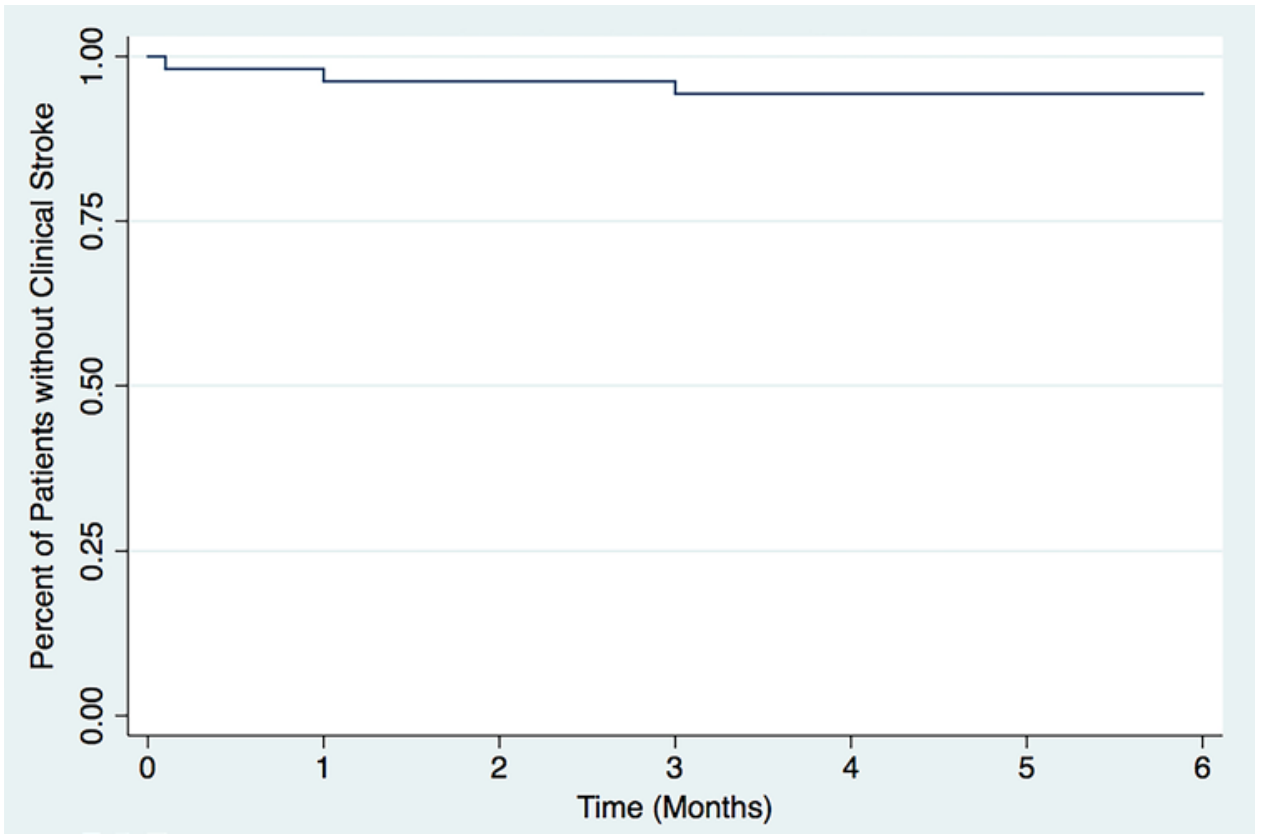

FIG. 2. Stroke-free clinical status from baseline to 6 months posttreatment. Figure is available in color online only.

patient was maintained on DAPT prior to the procedure and received systematic heparin throughout the intervention. A PED was deployed, starting from just proximal to the MCA bifurcation and ending in the supraclinoid ICA. The patient recovered well postoperatively and remained at her neurological baseline. After 1 night of observation in the neurointensive care unit, she was discharged home in good condition. The patient remained neurologically intact and was scheduled for her 1-year follow-up angiogram.

\section{Case 2}

A 58-year-old woman had an anterior communicating artery aneurysm that was discovered on a workup for headache and right-sided numbness. Angiography showed
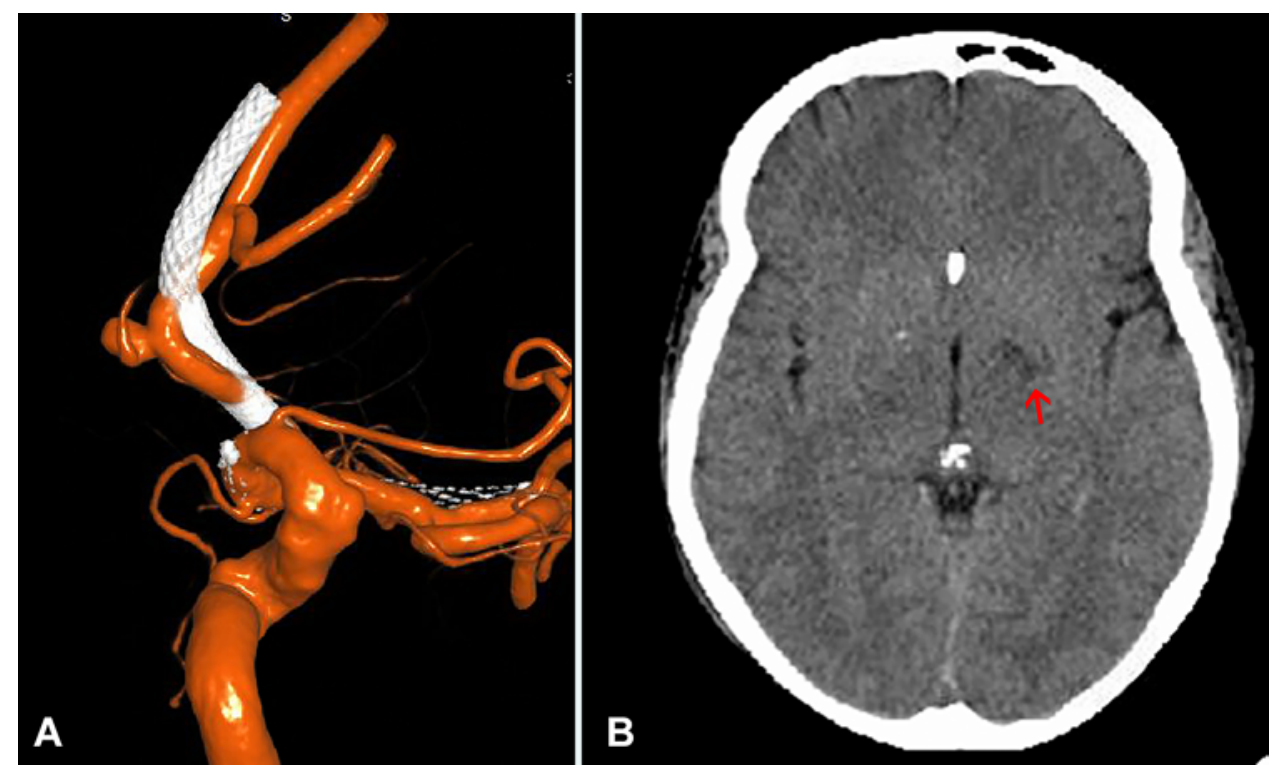

FIG. 3. Case 1. Example of a successful treatment. A: Three-dimensional rotational angiogram showing a 10-mm right $\mathrm{M}_{1}$ aneurysm with a $5.5-\mathrm{mm}$ neck arising proximal to the bifurcation, projecting superiorly and anteriorly. B: Noncontrast CT image. A PED was deployed, starting from just proximal to the MCA bifurcation, ending in the supraclinoid ICA. The arrow indicates an infarct in the vascular territory supplied by the lenticulostriate vessels, which were covered by the device. Figure is available in color online only. 


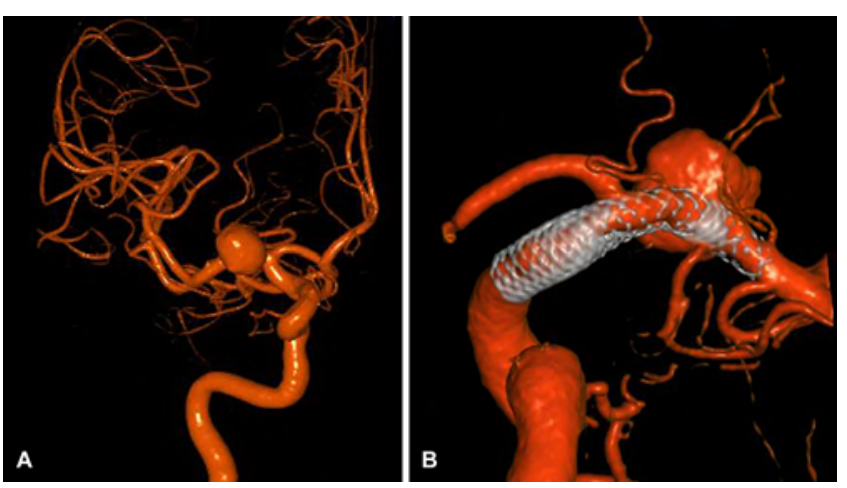

FIG. 4. Case 2. Example of a patient with small postprocedural infarcts. Angiogram showing a wide-necked irregular left $A_{1} / A_{2}$ junctional aneurysm, projecting posteriorly and medially (A). Intraprocedural proximal migration of the ACA PED into the MCA occurred, requiring emergency placement of an Enterprise stent as seen here in the ipsilateral MCA (B). Figure is available in color online only.

a wide-necked, irregular, left $\mathrm{A}_{1} / \mathrm{A}_{2}$ junctional aneurysm, projecting posteriorly and medially (Fig. 4), which was thought to be amenable to flow diversion therapy with the PED. The patient was maintained on DAPT prior to the procedure and received systematic heparin throughout the intervention. The procedure was complicated by proximal device migration following deployment, encroaching on the $M_{1}$ segment of the left MCA. This was treated with emergency placement of an Enterprise stent in the MCA across the PED to maintain the patency of the MCA. The subsequent angiogram showed platelet aggregation, which was treated with an intraarterial bolus of abciximab. Postintervention angiography showed reestablishment of brisk anterograde flow in both the ACA and MCA. The patient experienced right hemiplegia immediately postoperatively, which improved with time after inpatient rehabilitation. CT scanning showed infarcts in the left anterior frontal lobe and posterior limb of the left internal capsule (Fig. 4). At discharge, the patient was ambulating with a walker and able to perform activities of daily living without assistance.

\section{Case 3}

A 57-year-old woman with previously treated aneurysms was found to have an enlarging right ICA communicating segment aneurysm on surveillance imaging (Fig. 5). The patient underwent uneventful PED placement, with the distal end of the stent in the $\mathrm{M}_{1}$ segment. She was monitored in the neurointensive care unit and discharged on postoperative day 1 . Ten days later, she presented to the emergency department with acute-onset left hemiplegia and was found to have complete stent occlusion. She had not taken clopidogrel since her discharge. She underwent emergency thrombectomy, with postintervention reperfusion of the ICA and MCA. CT scanning of the head showed a new infarct in the lentiform nucleus (Fig. 5). She was restarted on a regimen of DAPT and ultimately recovered full function.

\section{Discussion}

With mounting safety and efficacy data, ${ }^{13}$ flow diversion treatment of intracranial aneurysms is becoming increasingly common, with successful series in treating small, complex, or distal pathologies. Here, we showed that covering the lenticulostriate vessels with FD does not lead to routine clinical evidence of ischemia in these territories in patients maintained on appropriate antiplatelet therapy.

Our series had 2 patients with clinical and radiographic infarcts in the lenticulostriate territory. One patient was noncompliant with antiplatelet therapy, emphasizing the importance of this regimen in patients treated with flow diversion, especially when small critical perforators are covered. Since her thrombectomy, the patient has returned to her neurological baseline, is taking her medication as prescribed, and has had no further events. The other patient had a clinical infarct in the MCA territory after placement of a flow diverter in the ACA that migrated, resulting in platelet aggregation and transient occlusion of both vessels. This patient had frontal infarcts, resulting from ACA occlusion distal to the lenticulostriate branches, and an infarct in the posterior limb of the internal capsule, likely re-
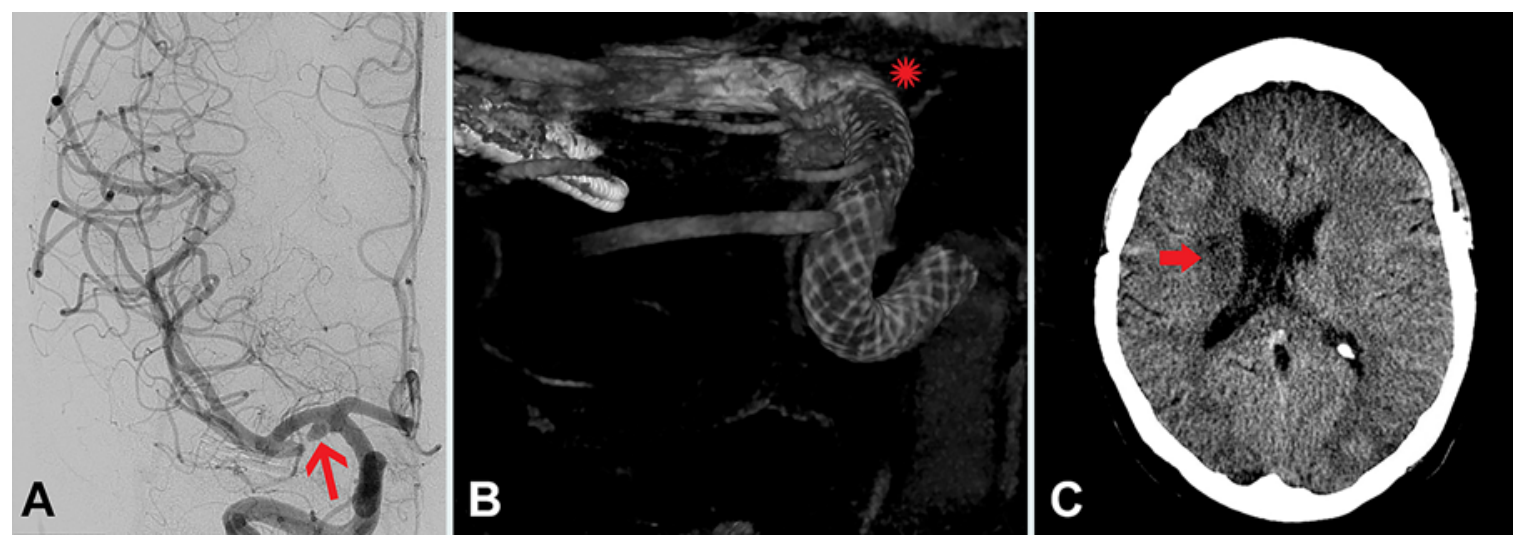

FIG. 5. Case 3. Example of a patient who suffered a posttreatment stroke. A: The patient had an enlarging right ICA communicating segment aneurysm on surveillance imaging (thick arrow). B: She underwent uneventful PED placement, with the distal end of the stent in the $\mathrm{M}_{1}$ (star), shown on this cone beam CT image. C: CT image of the head 10 days later showing a new infarct in the right lentiform nucleus (large arrow). Figure is available in color online only. 
TABLE 2. Covered side branch vessels and outcomes in the literature

\begin{tabular}{lcclll}
\hline \multicolumn{1}{c}{ Authors \& Year } & $\begin{array}{c}\text { No. of } \\
\text { Patients }\end{array}$ & $\begin{array}{c}\text { No. of Side } \\
\text { Branches Covered }\end{array}$ & \multicolumn{1}{c}{ Covered Vessels } & $\begin{array}{c}\text { No. of Covered Branch } \\
\text { Occlusions (modality) }\end{array}$ & \multicolumn{1}{c}{ Ischemia } \\
\hline Szikora et al., 2010 & 18 & 28 & OphA, PCoA, AChA, PICA, AICA & 3 (angiography) & $\begin{array}{c}\text { (periprocedural retinal } \\
\text { branch occlusion) }\end{array}$ \\
\hline Yavuz et al., 2014 & 21 & 21 & $\mathrm{M}_{2}$ branches & 3 (angiography) & 0 \\
\hline Neki et al., 2015 & 20 & 20 & AChA & 0 (angiography) & 0 \\
\hline Vedantam et al., 2015 & 49 & 74 & OphA, PCoA, AChA & 3 (angiography) & 0 \\
\hline Mazur et al., 2016 & 11 & 11 & PICA & 1 (angiography, MRI) & 0 \\
\hline Rangel-Castilla et al., 2017 & 82 & 127 & OphA, PCoA, AChA, ACA & 13 (angiography) & 0 \\
\hline Bhogal et al., 2017 & 140 & 285 & OphA, PCoA, AChA, ACA & 29 (angiography) & 5 (embolic on DWI MRI) \\
\hline
\end{tabular}

sulting from $\mathrm{M}_{1}$ lenticulostriate occlusion. In our series, no patients experienced clinical or radiographic (from those with imaging follow-up) lenticulostriate infarct due to lenticulostriate coverage by an FD if their platelet inhibition was appropriate.

Flow diverters are designed with a low porosity that diminishes flow to the treated aneurysm but still allows flow to the side branches of the parent vessel. ${ }^{14}$ Initial animal studies of the PED, which is a braided mesh cylinder with pore sizes ranging from 0.02 to $0.05 \mathrm{~mm}^{2},{ }^{3}$ showed no occlusion of branch vessels covered with the device., ${ }^{7,9}$

Clinical data have suggested that covering branch vessels is usually clinically well tolerated. ${ }^{21,27,29}$ Multiple series have shown that covering branches, including the ophthalmic artery $(\mathrm{OphA})$, posterior communicating artery $(\mathrm{PCoA})$, posterior inferior cerebellar artery (PICA), anterior inferior cerebellar artery (AICA), and anterior choroidal artery (AChA), do not lead to clinical sequelae (Table 2). 4,19,23,27,29 It is hypothesized that vessels with collateral supply (i.e., the OphA artery) are more likely to occlude, as there is an alternative blood supply, and demand from the covered vessel can diminish. Puffer et al. ${ }^{21}$ reported 20 aneurysms in which a flow diverter covered the OphA. One was noticed to immediately retrograde fill from collaterals, while 2 displayed slowed filling. At follow-up, the OphA was occluded in 4 patients, with slowed filling in an additional 2; all patients were asymptomatic. Conversely, terminal vessels with no known collaterals seem to be more resistant to occlusion; multiple studies have shown that these vessels remain patent after being covered with an FD. 19,23,27,29 These series suggest that demand through covered terminal vessels continues, as their territories have no other blood supply. This demand is sufficient to keep the ostia patent even when covered. However, even when occlusion of the terminal vessels is slow, it appears to be well tolerated. In the series by Yavuz et al., 21 MCA aneurysms were treated, with one of the $\mathrm{M}_{2}$ segments jailed; 3 were occluded at follow-up, and 6 demonstrated reduced flow. No occlusion resulted in clinical symptoms. ${ }^{30}$

Similar to the AChA and basilar perforators, the lenticulostriate vessels are terminal branches that supply critical structures. There are generally no anastomoses to supply their vascular territory, thus blood flow demand remains high after being covered. It is likely that this demand keeps the ostia patent. It is also possible that, if flow does decrease slowly, the ongoing demand drives the development of collaterals from other vessels that do not normally supply these territories. Just as aneurysms occlude over time, the ostia generally do not occlude immediately. If there is a slow decrease in flow, there is significant time to derive blood supply from other sources and prevent ischemia.

Despite the aforementioned encouraging series, there have been reports of occlusion of covered branch vessels after FD placement with clinical sequelae. Van Rooij and Sluzewski reported a lenticulostriate infarct that resulted in hemiparesis after placement of telescoping flow diverters in the proximal $\mathrm{A}_{1}$ despite appropriate antiplatelet therapy ${ }^{28}$ Lall et al. reported 3 cases of intraprocedural branch occlusion despite appropriate antiplatelet therapy. All patients were treated effectively with abciximab and recovered without clinical sequelae. ${ }^{16}$ There is some suggestion that covering an ostium with multiple devices may increase the rate of occlusion, although no results have been statistically significant. ${ }^{21}$ In our series, all lenticulostriate vessels were covered with one device, and we do not recommend overlapping devices in this perforator-rich zone. It is our philosophy at our institution to not use multiple devices in regions with critical side branches; thus, the results presented here cannot be applied to those specific cases.

Previous endovascular techniques have demonstrated silent infarct rates from $10 \%$ to $69 \%, 2,5,10,25$ and there is concern that the rates of silent infarcts after flow diversion treatment may be higher. A second study prospectively compared 41 patients treated with FDs compared with standard stent embolization, evaluated by FLAIR and diffusion-weighted imaging (DWI) changes on MRI obtained within 24 hours of the procedure. Patients undergoing FD treatment were significantly more likely to exhibit radiographic changes than those undergoing standard stent treatment $(54 \%$ vs $14 \%, \mathrm{p}<0.001)$. These changes were generally hemispheric and not in the territory of covered perforators; additionally, no patient experienced neurological symptoms related to new lesions. ${ }^{24}$ These strokes were generally diffuse cortical foci of restricted diffusion and attributed to an embolic phenomenon, as all devices were placed in the cavernous to ophthalmic segments of the ICA and no major vessels were occluded.

Iosif et al. ${ }^{11}$ found a high rate of radiographic infarcts. Thirty-eight consecutive patients underwent MRI between 24 and 48 hours after placement of an FD. DWI changes were seen in $92.1 \%$ of patients and were clinically significant in only $13.1 \%$. These changes were only seen in the 
territory of covered side branches in $22 \%$; this was not significantly different from the DWI findings in the distal territory of the stented vessel. Similar to previous studies and our series, the majority of patients with radiographic ischemia showed no clinical symptoms. ${ }^{11}$ Brasiliense et al. ${ }^{6}$ also evaluated imaging changes in a series of patients treated with FDs. Fifty-nine patients were prospectively treated with FDs, and DWI was performed within 24 hours in all patients. New lesions were identified on DWI in $62.7 \%$ of patients; however, $21.8 \%$ of these lesions were not in the territory of the treated vessel, and only $5.1 \%$ of patients experienced neurological symptoms. ${ }^{6}$ Flow diversion creates stasis of blood flow within the aneurysm, eventually leading to thrombosis and occlusion; however, in the immediate postprocedural time before occlusion, there is still flow into and out of the aneurysm. It is possible that this stasis allows for thrombus formation and embolization, but more likely that the thrombus was formed on the surface of these low porosity devices with subsequent embolization, leading to the significantly higher rate of radiographic infarcts seen in patients treated with flow diversion than in those treated with standard stenting. ${ }^{24}$

The clinical significance associated with these imaging changes remains unknown. In our series of 51 patients, only 3 patients had sustained neurological deficits, 2 of whom were noncompliant with dual antiplatelet therapy. As with any surgical technique, patient selection and counseling remain paramount. While flow diversion has revolutionized aneurysm treatment, it is not without risks; all surgical and endovascular interventions should be carefully considered for each individual patient. Patients who are selected for flow diversion are maintained on DAPTs, which are carefully monitored. Strict adherence to the regimen on the part of the patient and meticulous monitoring on the part of the clinical team are essential to minimize complications; as presented here, the 2 cases of in-stent thrombosis occurred in patients who were off DAPT. Patients must be extensively counseled on the importance of the DAPT regimen prior to intervention, especially in cases in which critical perforators are covered.

\section{Study Limitations}

This study is limited in its retrospective design and the small number of patients. Additionally, imaging was not performed in all patients, but rather only in those who demonstrated clinical symptoms. Radiographic and clinical outcomes were assessed by the treating team and not a blinded reviewer. It is possible that a greater number of patients experienced radiographic infarcts in the lenticulostriate territory but remained asymptomatic, and future studies with prospectively collected MRI and clinical outcomes are needed to delineate this. This study is also subject to selection bias, as some patients were treated with FDs based on surgeon preference.

\section{Conclusions}

Flow diversion is gaining widespread used in increasingly varied pathology. Here, we showed that placement of flow diverters in the $M_{1}$ and $A_{1}$ segments, covering the lenticulostriate vessels, does not routinely lead to a clinically relevant perforator distribution infarct in patients who are appropriately inhibited with DAPT. However, larger studies with follow-up imaging are needed to corroborate our findings.

\section{References}

1. Adeeb N, Griessenauer CJ, Foreman PM, Moore JM, Shallwani $\mathrm{H}$, Motiei-Langroudi $\mathrm{R}$, et al: Use of platelet function testing before Pipeline Embolization Device placement: a multicenter cohort study. Stroke 48:1322-1330, 2017

2. Altay T, Kang HI, Woo HH, Masaryk TJ, Rasmussen PA, Fiorella DJ, et al: Thromboembolic events associated with endovascular treatment of cerebral aneurysms. J Neurointerv Surg 3:147-150, 2011

3. Becske T, Kallmes DF, Saatci I, McDougall CG, Szikora I, Lanzino G, et al: Pipeline for uncoilable or failed aneurysms: results from a multicenter clinical trial. Radiology 267:858868,2013

4. Bhogal P, Ganslandt O, Bäzner H, Henkes H, Pérez MA: The fate of side branches covered by flow diverters-results from 140 patients. World Neurosurg 103:789-798, 2017

5. Biondi A, Oppenheim C, Vivas E, Casasco A, Lalam T, Sourour N, et al: Cerebral aneurysms treated by Guglielmi detachable coils: evaluation with diffusion-weighted MR imaging. AJNR Am J Neuroradiol 21:957-963, 2000

6. Brasiliense LB, Stanley MA, Grewal SS, Cloft HJ, Sauvageau E, Lanzino G, et al: Silent ischemic events after Pipeline embolization device: a prospective evaluation with MR diffusion-weighted imaging. J Neurointerv Surg 8:1136-1139, 2016

7. Cebral JR, Raschi M, Mut F, Ding YH, Dai D, Kadirvel R, et al: Analysis of flow changes in side branches jailed by flow diverters in rabbit models. Int J Numer Methods Biomed Eng 30:988-999, 2014

8. Colby GP, Bender MT, Lin LM, Beaty N, Huang J, Tamargo RJ, et al: Endovascular flow diversion for treatment of anterior communicating artery region cerebral aneurysms: a single-center cohort of 50 cases. J Neurointerv Surg 9:679685, 2017

9. Dai D, Ding YH, Kadirvel R, Rad AE, Lewis DA, Kallmes DF: Patency of branches after coverage with multiple telescoping flow-diverter devices: an in vivo study in rabbits. AJNR Am J Neuroradiol 33:171-174, 2012

10. Hahnemann ML, Ringelstein A, Sandalcioglu IE, Goericke S, Moenninghoff C, Wanke I, et al: Silent embolism after stent-assisted coiling of cerebral aneurysms: diffusionweighted MRI study of 75 cases. J Neurointerv Surg 6:461465, 2014

11. Iosif C, Camilleri Y, Saleme S, Caire F, Yardin C, Ponomarjova $\mathrm{S}$, et al: Diffusion-weighted imaging-detected ischemic lesions associated with flow-diverting stents in intracranial aneurysms: safety, potential mechanisms, clinical outcome, and concerns. J Neurosurg 122:627-636, 2015

12. Kallmes DF, Brinjikji W, Boccardi E, Ciceri E, Diaz O, Tawk $\mathrm{R}$, et al: Aneurysm Study of Pipeline in an Observational Registry (ASPIRe). Intervent Neurol 5:89-99, 2016

13. Kallmes DF, Brinjikji W, Cekirge S, Fiorella D, Hanel RA, Jabbour P, et al: Safety and efficacy of the Pipeline embolization device for treatment of intracranial aneurysms: a pooled analysis of 3 large studies. J Neurosurg 127:775-780, 2017

14. Kallmes DF, Ding YH, Dai D, Kadirvel R, Lewis DA, Cloft HJ: A new endoluminal, flow-disrupting device for treatment of saccular aneurysms. Stroke 38:2346-2352, 2007

15. Kallmes DF, Hanel R, Lopes D, Boccardi E, Bonafé A, Cekirge $S$, et al: International retrospective study of the pipeline embolization device: a multicenter aneurysm treatment study. AJNR Am J Neuroradiol 36:108-115, 2015

16. Lall RR, Crobeddu E, Lanzino G, Cloft HJ, Kallmes DF: 
Acute branch occlusion after Pipeline embolization of intracranial aneurysms. J Clin Neurosci 21:668-672, 2014

17. Mazaris P, Mehta T, Hussain M, Inoa V, Singer J, Spiegel $\mathrm{G}$, et al: Endovascular treatment of complex distal posterior cerebral artery aneurysms with the Pipeline Embolization Device. World Neurosurg 107:1043.e1-1043.e5, 2017

18. Mazur MD, Kilburg C, Wang V, Taussky P: Pipeline embolization device for the treatment of vertebral artery aneurysms: the fate of covered branch vessels. J Neurointerv Surg 8:1041-1047, 2016

19. Neki H, Caroff J, Jittapiromsak P, Benachour N, Mihalea C, Ikka L, et al: Patency of the anterior choroidal artery covered with a flow-diverter stent. J Neurosurg 123:1540-1545, 2015

20. Patel PD, Chalouhi N, Atallah E, Tjoumakaris S, Hasan D, Zarzour H, et al: Off-label uses of the Pipeline embolization device: a review of the literature. Neurosurg Focus 42(6):E4, 2017

21. Puffer RC, Kallmes DF, Cloft HJ, Lanzino G: Patency of the ophthalmic artery after flow diversion treatment of paraclinoid aneurysms. J Neurosurg 116:892-896, 2012

22. Rajah G, Narayanan S, Rangel-Castilla L: Update on flow diverters for the endovascular management of cerebral aneurysms. Neurosurg Focus 42(6):E2, 2017

23. Rangel-Castilla L, Munich SA, Jaleel N, Cress MC, Krishna C, Sonig A, et al: Patency of anterior circulation branch vessels after Pipeline embolization: longer-term results from 82 aneurysm cases. J Neurosurg 126:1064-1069, 2017

24. Safain MG, Roguski M, Heller RS, Malek AM: Flow diverter therapy with the Pipeline Embolization Device is associated with an elevated rate of delayed fluid-attenuated inversion recovery lesions. Stroke 47:789-797, 2016

25. Soeda A, Sakai N, Murao K, Sakai H, Ihara K, Yamada N, et al: Thromboembolic events associated with Guglielmi detachable coil embolization with use of diffusion-weighted MR imaging. Part II. Detection of the microemboli proximal to cerebral aneurysm. AJNR Am J Neuroradiol 24:20352038, 2003

26. Srinivasan VM, Ghali MGZ, Cherian J, Mokin M, Puri AS, Grandhi R, et al: Flow diversion for anterior choroidal artery (AChA) aneurysms: a multi-institutional experience. J Neurointerv Surg 10:634-637, 2018

27. Szikora I, Berentei Z, Kulcsar Z, Marosfoi M, Vajda ZS, Lee $\mathrm{W}$, et al: Treatment of intracranial aneurysms by functional reconstruction of the parent artery: the Budapest experience with the pipeline embolization device. AJNR Am J Neuroradiol 31:1139-1147, 2010
28. van Rooij WJ, Sluzewski M: Perforator infarction after placement of a pipeline flow-diverting stent for an unruptured A1 aneurysm. AJNR Am J Neuroradiol 31:E43-E44, 2010

29. Vedantam A, Rao VY, Shaltoni HM, Mawad ME: Incidence and clinical implications of carotid branch occlusion following treatment of internal carotid artery aneurysms with the pipeline embolization device. Neurosurgery 76:173-178, 2015

30. Yavuz K, Geyik S, Saatci I, Cekirge HS: Endovascular treatment of middle cerebral artery aneurysms with flow modification with the use of the pipeline embolization device. AJNR Am J Neuroradiol 35:529-535, 2014

31. Yeung TW, Lai V, Lau HY, Poon WL, Tan CB, Wong YC: Long-term outcome of endovascular reconstruction with the Pipeline embolization device in the management of unruptured dissecting aneurysms of the intracranial vertebral artery. J Neurosurg 116:882-887, 2012

\section{Disclosures}

Dr. Thomas: support of non-study-related clinical or research effort from Stryker. Dr. Mokin: consultant for Penumbra, Inc. Dr. Puri: consultant for Stryker Neurovascular and Medtronic; direct stock ownership in InNeuroCo; and support of non-studyrelated clinical or research effort from Stryker Neurovascular and Metronic.

\section{Author Contributions}

Conception and design: Kan, Ghali. Acquisition of data: Kan, Thomas, Enriquez-Marulanda, Alturki, Ogilvy, Mokin, Puri, Grandhi, Chen, Johnson. Analysis and interpretation of data: Kan, Wagner, Srivatsan, Ghali, Thomas, Enriquez-Marulanda, Alturki, Ogilvy, Kuhn, Puri, Grandhi, Chen, Johnson. Drafting the article: Wagner, Ghali. Critically revising the article: Kan, Wagner, Srinivasan, Ghali, Thomas, Alturki, Ogilvy, Mokin, Puri, Grandhi. Reviewed submitted version of manuscript: Kan, Wagner, Ghali, Thomas, Alturki, Ogilvy, Mokin, Kuhn, Puri, Grandhi, Chen, Johnson. Approved the final version of the manuscript on behalf of all authors: Kan. Administrative/technical/material support: Kan, Ghali. Study supervision: Kan.

\section{Correspondence}

Peter Kan: Baylor College of Medicine, Houston, TX.peter.kan@ bcm.edu. 